\title{
Tragic Choices: Autonomy and Emotional Responses to Medical Decisions
}

\author{
SIMONA BOTTI \\ KRISTINA ORFALI \\ SHEENA S. IYENGAR*
}

\begin{abstract}
We investigate how making highly consequential, highly undesirable decisions affects emotions and preference for autonomy. We examine individuals facing real or hypothetical decisions to discontinue their infants' life support who either choose personally or have physicians choose for them. Findings from a multidisciplinary approach consisting of a qualitative analysis of in-depth interviews and three laboratory studies reveal that perceived personal causality for making tragic decisions generates more negative feelings than having the same choices externally made. Tragic decisions also undermine coping abilities, weakening the desire for autonomy. Consequently, participants disliked making decisions but also resented relinquishing their option to choose.
\end{abstract}

\begin{abstract}
I wanted them to decide-doctors I had never met before. . . . I could not bear the possibility of making the wrong call. Even if I made what I was sure was the right choice for her, I could not live with the guilt if something went wrong. (Gawande 2002)
\end{abstract}

$\mathrm{I}$ magine being in Atul Gawande's position. A decision needs to be made as to which medical treatment is best for your suffering premature daughter. Her long-term health

*Simona Botti is assistant professor of marketing, London Business School, London NW1 4SA (sbotti@london.edu). Kristina Orfali is associate clinical professor of bioethics in pediatrics and faculty fellow, Institute for Social and Economic Research and Policy (ISERP), and faculty associate, Center for Bioethics, Columbia University, College of Physicians and Surgeons, Division of Neonatology, Department of Pediatrics, 3959 Broadway, CHN 2101, New York, NY 10032-3784 (ko2145@columbia .edu). Sheena S. Iyengar is professor of management, 714 Uris Hall, Columbia University Graduate School of Business, 3022 Broadway, New York, NY 10027-6902 (siyengar@ columbia.edu). Correspondence: Simona Botti. Simona Botti is grateful for the financial support provided by the 2006 Clifford H. Whitcomb Faculty Fellowship, Johnson Graduate School of Management, Cornell University. Kristina Orfali gratefully acknowledges grant support from the Institute of Social Research and Policy. Sheena S. Iyengar would like to thank the National Science Foundation for contributing funds and resources toward supporting the studies reported in this investigation. The authors thank John Remarek for his assistance throughout the writing process and Alessandra Payne, Caroline Alvarez, and Lucy Huang for their help with data collection. The authors would also like to acknowledge the invaluable guidance of the editor, associate editor, and reviewers.

John Deighton served as editor and Mary Frances Luce served as associate editor for this article.

Electronically published April 2, 2009 and survival are at stake. Do you want to make the choice or would you rather have someone else choose, even if a stranger? And, once the decision is made, does the knowledge that you chose help you cope better even if the result is traumatic?

The decision illustrated above falls at the extreme ends of two continua, one varying in the valence of the outcome, from desirable to undesirable, and the other varying in the importance of the outcome, from mundane to highly consequential. Highly undesirable, highly consequential decisions almost transcend the concept of choice as they cause individuals to face tragic dilemmas that generate severe emotional upset. These tragic choices are particularly notable in the domain of health care, where people are increasingly likely to make excruciating, highly momentous decisions for themselves and the members of their families (Schneider 1998; Schwartz 2004). For example, between $40 \%$ and $90 \%$ of the deaths in intensive care units are today caused by deliberate decisions to interrupt life-sustaining therapy (McLean et al. 2000).

Since the time of Hippocrates, doctors' mandate was to choose on behalf of their patients, who were believed to be cognitively and emotionally unprepared to make decisions in their best interest. Even today, physicians take the oath to "follow that system of regimen which, according to my ability and judgment, I consider for the benefit of my patients" (Oath of Hippocrates, ca. 400 BC/1910). In the last 30 years, this paternalistic model of medical decision making has been gradually replaced in most Western countries by a mandatory model of autonomy according to which patients have the right to make informed choices. The autonomous model presupposes that patients know their risk 
aversion and desired quality of life better than doctors. Although physicians can identify the alternative that is superior according to established medical criteria, only the informed patients can, and should, select the treatment that most benefits their subjective well-being (Katz 1984; Schneider 1998; Wong and King 2008).

Increasingly, then, individuals are asked to make tragic decisions, but the psychological effects of these decisions have been rarely investigated in consumer behavior research. As noted by Kahn and Luce (2003), consumer researchers have examined emotionally demanding choices primarily in mundane contexts, in which the postponement of these decisions is a viable option. The emotional distress associated with these mundane choices does not result from the high stakes that they involve but, rather, from uncertainty about which option is best (Chernev 2003; Dhar 1997; Shafir, Simonson, and Tversky 1993) combined with demotivating cognitive effort (Garbarino and Edell 1997; Iyengar and Lepper 2000), trade-offs among highly valued goals (Luce 1998; Luce, Bettman, and Payne 1997), or regret for the forsaken alternatives (Carmon, Wertenbroch, and Zeelenberg 2003; Schwartz et al. 2002). By comparison, this article examines consumers' responses to unavoidable choices that, as illustrated by the opening quotation, are so highly consequential as to be emotionally painful even when the "best" option is known.

Specifically, we study how making a tragic choice, versus having the same tragic choice externally made, affects individuals' desire for autonomy and their emotional reactions to the same decision outcome. Prior research has shown that the sense of agency and internal locus of control associated with the act of choosing lead to perceptions of personal causality, whereas the imposition of a choice is removed from the idea of personal causality because it presupposes an external, rather than internal, locus of control (Brehm 1966; deCharms 1968; Deci and Ryan 1985; Langer 1975; Seligman 1975; Taylor and Brown 1988). Stronger causal ascriptions, in turn, have been found to magnify the intensity of emotional responses to an event, so that perceptions of personal causation intensify positive affect from desirable outcomes but also enhance negative affect from undesirable outcomes (Gilovich, Medvec, and Chen 1995; Landman 1987; Ritov and Baron 1995; Weiner 1986). Thus, we hypothesize that a decision outcome following a tragic choice will generate more extreme negative emotions when it is personally chosen because of a greater sense of causality; in contrast, when the same tragic choice is externally determined, negative emotions will be lessened by the perceived absence of a causal link with the aversive experience.

Yet the torments of making tragic choices do not necessarily reduce people's desire for autonomy. Prior research has shown that consumers confronted with choices that detrimentally affect their well-being still prefer making these choices themselves rather than having the same choices made for them by somebody else (Botti and Iyengar 2004; Botti and McGill 2006). This desire for choice in spite of its negative consequences can be attributed to consumers' belief that they will maximize subjective utility by selecting the option that best matches personal preferences (Hotelling 1929). Even when individuals are unaware of their preferences, choosing activates a psychological immune system that facilitates preference matching by subjectively bolstering the value of a personally selected outcome (Gilbert et al. 1998). Through subjective bolstering decision makers are able to reduce the emotional discomfort of decisions that may not be consistent with individual preferences by convincing themselves and others that they had chosen the bestmatching option (Brehm 1966; Festinger 1957; Shafir et al. 1993). However, research has shown that in the case of highstakes decisions such as those investigated in this article, the ensuing emotional distress both weakens personal preferences (Kahn and Baron 1995; Katz 1984) and undermines normal coping resources and mechanisms (Dunn and Wilson 1990; Hoff 2001). We therefore predict that in the context of tragic choices, which are highly emotional and highly consequential, subjective choice bolstering will be impaired. Thus, in contrast with previous findings in the consumer behavior literature, we hypothesize that the provision and exercise of tragic choices will attenuate desire for decision autonomy.

Our hypotheses were inspired by recent insights from a rich ethnographic investigation conducted by Orfali and her colleagues (Orfali 2004; Orfali and Gordon 2004). Their work is part of a growing body of research in bioethics that criticizes the benefits subsumed by the autonomy paradigm with studies showing that decision making in dramatic contexts requires specific cognitive, emotional, and ethical adjustments. As in consumer behavior, this literature assumes a generalized preference for choice, although the empirical evidence supporting individuals' desire for autonomy in extreme situations, such as end-of-life decisions, is inconclusive and limited (Guadagnoli and Ward 1998). In contrast with this assumption, the study conducted by Orfali and colleagues suggests that the autonomous model of medical decision making may have detrimental effects for the experience of parents in neonatal intensive care units (NICUs).

Orfali and colleagues contrast two countries that have adopted different medical decision-making models: the United States, which has embraced the autonomous model requiring parents to personally decide their children's treatments, and France, which has retained the paternalistic model in the field of neonatology, leaving treatment decisions to physicians. Observations and in-depth interviews with both parents and the medical teams suggested that French parents coped better with the upsetting events experienced in the NICUs than American parents. In addition, both sets of parents appeared to be ambivalent about having decision-making power, simultaneously desiring and resenting having more control over decisions affecting their children's lives. These data allow for a deep understanding of French and American parents' decision-making processes and raise important questions about the role of autonomy in medical decision making.

The objective of this ethnographic study differs from that 
of the current investigation as it does not concern itself with the psychological consequences of tragic choices but instead examines medical decisions that vary in the severity of their impact, from performing routine examinations to deciding whether or not to continue life-sustaining treatment, and decision outcomes that vary in their valence, from the full recovery of the baby to the baby's death. Hence, the responses of French and American parents capture more general differences in satisfaction between the two NICUs. The questions remain: Would parents deprived of their decision autonomy still be better off than the more autonomous parents if tragic choices, rather than their overall experience, were considered? Would they still be ambiguous about their preference for choosing?

For the purpose of the current investigation we extracted a subset of data from the larger ethnographic study conducted by Orfali and colleagues (Orfali 2004; Orfali and Gordon 2004). This subset included only interviews with parents whose babies died after the physicians offered the option to interrupt the life-sustaining treatment and who either autonomously made this tragic decision (United States) or simply witnessed the physicians deciding on their behalf (France). The choice of withdrawing life-sustaining treatment is tragic not only because it is highly consequential but because it is greatly emotionally distressing even if it represents the optimal alternative for the types of medical conditions considered in the subset (Orfali 2004). We conducted in-depth analyses of these interviews to look for emerging recurrent themes and test whether the negative effect of choice on emotions and preference for autonomy that was found in the broader study with respect to various medical decisions and decision outcomes persisted with respect to the same traumatic decision (withdrawal of life support) and dismal outcome (death of the child).

This in-depth analysis of the subset of interviews directly tested the hypothesized effects but not the proposed explanation that the greater extent of perceived causality associated with autonomous, as compared to other-made choices, magnifies parents' negative emotional response to a tragic outcome. The French and American NICUs compared by Orfali and colleagues (Orfali 2004; Orfali and Gordon 2004) varied systematically across factors that, aside from the autonomy granted by the two medical decision-making models, could account for the observed differences. First, Orfali (2004) proposes that a blunt distinction between the two models is misleading and that American parents' greater decision-making autonomy was limited by the doctors' willingness to consent to such autonomy. For instance, withdrawal of care was often offered in the case of moribund babies, whose death was highly likely although not necessarily immediate. Parents, nonetheless, perceived this choice as one between life and death because they were asked to consent to a withdrawal of care that would shorten their baby's life. Still, the question about how parents' responses vary as a function of actual differences in the extent of parental autonomy is open.

Second, French and American doctors differed in the level of information they provided to the parents. French physicians appeared to offer less information about treatment alternatives than their American counterparts, or even no information at all, with the intent to reduce the uncertainty of the prognoses (Orfali 2004), simplify the decision making, and protect the parents' psychological well-being (Orfali and Gordon 2004).

Third, the French and American contexts varied in the level of emotional support offered by the organization, with U.S. parents suffering from lack of continuity of care and more frequent shifting of medical teams. Orfali and Gordon (2004, 349) explicitly recognize that disentangling organizational consistency from decision-making models is particularly challenging and that "it is unclear if a better organizational system within the autonomy framework could better answer the parents' needs or if the autonomy model is problematic in itself." At a broader level, differences in the social and cultural environment may have affected parents' responses as cultures vary in the level of confidence in authority figures, such as physicians (Hofstede 2001), and in general happiness (Kahneman and Riis 2005). This concern is, however, partially mitigated by the observed similarities in the parental narratives. These narratives expressed similar expectations and needs and suggested an unforeseen common NICU experience that transcended cultural, societal, and contextual differences, allowing for a more fruitful comparison of the respective ethical frameworks.

Building on the findings from the subset of interviews extracted from the larger ethnographic study, we conducted three follow-up laboratory studies to isolate the perceived causality explanation from the alternatives raised by Orfali and her colleagues. In the first study we presented undergraduate students at Cornell University with scenarios illustrating a situation analogous to the real-life context described in the interviews. We asked the students to imagine being the parents of a severely ill baby in a NICU who either had to choose themselves or witness the doctors choosing whether or not to withdraw life-sustaining therapy. This hypothetical examination allowed us to test our hypotheses among people who were not engaged in the emotional turmoil generated by tragic choices. Equally important, this study controlled for the possibility that differences in emotions and desire for autonomy between choosers and nonchoosers depend on the amount of information offered by the physicians, and the subsequent level of decision uncertainty, rather than on the level of participants' perceived causality. Study 2 tested the same hypotheses, this time controlling for participants' treatment preferences. Then, study 3 went one step further by framing the tragic life-anddeath decision as being inevitable. This framing enabled us to decrease decision makers' perceived causality, thereby directly testing the effect of personal causation on participants' responses. Collectively, with the laboratory studies we could manipulate choice provision while keeping constant the ways in which parents and medical staff interacted. This, together with the random assignment of participants with different cultural backgrounds to the experimental 
groups, allowed us to control for systematic differences in cultural traits or parent-medical staff relationships across conditions. By comparing the responses of such seemingly not comparable populations, undergraduates versus bereaved parents, we examined whether the emotional experiences of people who were not directly involved in tragic choices could be similar to the experiences of those who were. Such a question is of both theoretical and practical relevance given that most policy makers engage in perspective taking, a procedure akin to making judgments based on hypothetical scenarios, when determining important medical policies.

By employing a multidisciplinary method that combines qualitative and quantitative data, we approached the same problem from different perspectives, cross-examining a reallife dramatic choice context with the decontextualized setting of a controlled laboratory environment and integrating the findings for purposes of triangulation (Fine and Elsbach 2000). Qualitative data offered a deep understanding of the psychological turmoil associated with tragic choices, the complexity of which could not be fully captured solely by laboratory studies, thereby improving the practical relevance and generalizability of our findings. Quantitative data gave us the opportunity to measure the effects of choice on emotions and desire for autonomy, simplify the theory by testing a theoretical explanation while controlling for alternative ones, and propose a potential way to assuage the excruciating psychological unrest resulting from tragic choices.

\section{QUALITATIVE STUDY}

\section{Method}

In this study we examined a subset of interviews drawn from a larger comparative ethnographic research study on parents' experiences in NICUs (Orfali 2004; Orfali and Gordon 2004). The larger study used observations of participants from over 18 months in French and U.S. NICUs, as well as in-depth, semi-structured interviews with 60 clinicians and 75 parents, extracting data from more than 85 cases of severely ill newborns. No incentives were offered to the interviewees, whose interviews lasted from 25 minutes to 5 hours. This study followed the grounded theory approach, allowing for a comparative analysis of experiences across parents (Strauss and Corbin 1990), and relied on the classical criteria of credibility (the researchers' account is faithful to the experiences of informants), confirmability (different readers of the same material would arrive at the same conclusions), saturation (data are collected until redundancies emerge), and transferability (the conclusions of the study can be transferred to other contexts). The researchers followed NICU rounds, attended meetings with families and social workers and ethics consults (in the United States), and conducted informal meetings with physicians, social workers, and ethicists before approaching parents. The paucity of existing data in the medical field testifies to the many hurdles to be overcome when interviewing families in such tragic situations (Pinch 2002). Nonetheless, interviews can become a therapeutic encounter in which participants reconstruct painful life events into more positive and enabling narratives (Birch and Miller 2000; Gentry et al. 1995; Orfali and Gordon 2004; Pavia and Mason 2004). Only six parents approached to take part in this study declined to be interviewed.

Nineteen interviews were selected strictly following two criteria: (1) a decision was made to limit life support by withholding care, withdrawing ventilation, and/or precluding resuscitation ("do not resuscitate" orders); (2) the baby died as a result of the decision. The majority of neonatologists agree that treatment limitation is nearly certain to cause the death of the baby, whereas its continuation has a slightly higher likelihood of survival though in a severely impaired neurological state. Only in extremely rare cases can recovery surpass this dismal initial prognosis. Critical to the inquiry of this investigation, the treatment limitation decision was made by the parents in the United States, where parental autonomy prevails in the field of neonatology, and by the physicians in France, where parental consent is taken for granted (Orfali 2004). The subsample analyzed for the first time in this study focused on a specific real-life medical decision (treatment withdrawal) and outcome (the baby's death) to examine our research questions about the role of perceived causality in explaining how personally making a tragic choice, compared to having the same choice externally dictated, influences emotions and desire for autonomy.

Like other ethnographic studies that deal with sensitive issues (Bonsu and Belk 2003; Gentry et al. 1995; Pavia and Mason 2004), we approached respondents with great care. A review of the literature on families' reactions to withdrawal of life-sustaining therapy found no consensus regarding the optimal time for interviewing family members after the death of a patient, with reported time lags spanning between 1 week and 5 years (Mayer and Kossoff 1999). The 19 selected parents (nine in the United States and 10 in France) were, therefore, contacted 2-3 months after the baby's death. A letter introduced the research and requested their permission to be called within 3 weeks to discuss their experience. The wording of the letter was defined in collaboration with a chaplain and thanatologist. A thanatologist (Greek thanatos, $\theta \alpha \nu \alpha \tau o$ - death) is a professional specialized in dealing with death, dying, and bereavement. The thanatologist on site helped families, clinicians, and medical students cope with death-related issues. Some parents preferred to be interviewed by phone, while others scheduled a meeting at a venue of their choice. Parents could interrupt the interview if they became emotional or upset, but all of them chose to continue. Some were even grateful for the opportunity to share their experience, such as Debra (United States): "I hadn't talked about it for a while, but I guess it's good to talk about it once in a while. I guess the more I talk, the more I feel I'm doing better and better with it. I keep surprising myself." A profile of the interviewees appears in table 1 . All names are fictitious.

The interviewers began by asking broadly about the NICU experience. The topics emerging from the parents' subjec- 
TABLE 1

PROFILE OF PARTICIPANTS

\begin{tabular}{|c|c|c|c|c|}
\hline Parents & Children & $\mathrm{NICU}$ & Birth conditions & Parents' information \\
\hline Andrea & Carter & U.S. & Prematurity & NA \\
\hline Betty & Barbara & U.S. & Cerebral anoxia & Married \\
\hline Bridget & Eliot & U.S. & $\begin{array}{l}\text { 23-week gestation, } 1 \mathrm{lb} .35 \text { oz., kid- } \\
\text { ney failure }\end{array}$ & $\begin{array}{l}\text { Single, on public aid, other } \\
\text { children }\end{array}$ \\
\hline Debra & Elizabeth & U.S. & 6 lbs. 13 oz., hypoplastic heart & Married, two children \\
\hline Ellen & Lesley & U.S. & Died at 14 days & Single, employed \\
\hline Felicia & Julie & U.S. & Very low birth weight & Lived with baby's father \\
\hline & Alica & U.S. & 30-week gestation, $1 \mathrm{lb} .40 \mathrm{oz}$. & Employed, lives with father \\
\hline Melissa & Meredith & U.S. & $\begin{array}{l}\text { Almost full-term gestation, } 6 \text { lbs., } \\
\text { pulmonary hypertension }\end{array}$ & $\begin{array}{l}\text { Lived with baby's father, another } \\
\text { child }\end{array}$ \\
\hline Sharon & Charlie (twin Ben survived) & U.S. & $\begin{array}{l}\text { 33-week gestation, } 3 \text { lbs. } 3 \mathrm{oz} \text {., re- } \\
\text { spiratory problems }\end{array}$ & Married, two children \\
\hline Aline and Pierre & Alice & $\mathrm{Fr}$ & $\begin{array}{l}\text { 32-week gestation, } 1,780 \mathrm{~g} \text {, respira- } \\
\text { tory problems, infection }\end{array}$ & $\begin{array}{l}\text { Married, late thirties, computer } \\
\text { scientist, another son }\end{array}$ \\
\hline Annie & Alex and Claire & $\mathrm{Fr}$ & $\begin{array}{l}\text { 24-week gestation, cerebral, pulmo- } \\
\text { nary hemorrhage }\end{array}$ & Married; twins were first children \\
\hline Corinne & Laure (twin Francoise survived) & $\mathrm{Fr}$ & $\begin{array}{l}\text { 25-week gestation, respiratory } \\
\text { problems }\end{array}$ & $\begin{array}{l}\text { Employed and married; in vitro } \\
\text { fertilization }\end{array}$ \\
\hline Delphine & Marie & $\mathrm{Fr}$ & $\begin{array}{l}\text { 28-week gestation, } 1,000 \mathrm{~g} \text {, rhesus } \\
\text { incompatibility }\end{array}$ & Married, three daughters \\
\hline Denise and Patrick & Arianne & $\mathrm{Fr}$ & Full-term gestation, cerebral anoxia & Lived together \\
\hline Gabrielle & Bernard (twin Mathias survived) & $\mathrm{Fr}$ & $\begin{array}{l}\text { 6-month gestation, cerebral } \\
\text { hemorrhage }\end{array}$ & Married, two daughters \\
\hline Giselle & Amelie (twin Louise survived) & $\mathrm{Fr}$ & 27-week gestation, $800 \mathrm{~g}$, infection & Married \\
\hline Monica & Therese & $\mathrm{Fr}$ & $\begin{array}{l}\text { 31-week gestation, } 760 \mathrm{~g} \text {, } \\
\text { hypotrophy }\end{array}$ & Married, another son \\
\hline Nora & $\begin{array}{l}\text { Laurent and Noah (Noah died in } \\
\text { the delivery room) }\end{array}$ & $\mathrm{Fr}$ & 25-week gestation & $\begin{array}{l}\text { Lived with baby's father; nurse in } \\
\text { an ICU }\end{array}$ \\
\hline Sabine & Alain & $\mathrm{Fr}$ & $\begin{array}{l}\text { 31-week gestation, growth } \\
\text { retardation }\end{array}$ & $\begin{array}{l}\text { Married, engineer; Alain was first } \\
\text { son }\end{array}$ \\
\hline
\end{tabular}

NOTE.-U.S. = United States, Fr = France.

tive appraisals were followed by semi-structured questions aimed at understanding their emotional responses (e.g., "What has it been like for you having your child in the NICU?" "How is your life different since your baby has been in the NICU?") as well as their preference for involvement and autonomy in decision making (e.g., "Would you have felt relieved to leave it to the doctors to decide?" "Would you have preferred deciding yourself about your baby's treatment? Why?"). More direct questions were asked only if the parents did not raise these topics on their own. The interviews with French parents were conducted in French and translated into English by two independent translators. Each translator converted half of the interviews and then reviewed her colleague's drafts of the other half.

\section{Results}

We analyzed the selected subset of in-depth interviews by examining domains of convergence and divergence and identifying the recurring themes emerging from the narratives (Strauss and Corbin 1990).

Grief, Distress, and Coping. While the death of a child is an agonizing experience for any parent, most of the French parents did not express the same level of grief and distress as their American counterparts, as in the words of Delphine:
"Maybe it will come after, I do not know, but for the time being I found myself very courageous. . . . I told myself that we had to accept it"; and Nora: "Despite our misery, there weren't only bad moments. It is sad but if he's dead, it is because he had to die. When he died we were very sad, the relief was to tell ourselves, it's over."

In contrast, U.S. parents often reported high levels and greater persistence of psychological pain preventing them from reaching closure. This is evident in the case of Sharon: "I think of him every day. At my six week checkup they said I was going through postpartum depression." The struggle to cope with the loss of a child is a recurrent theme in the American parents' narratives. Initially, Debra seemed able to cope better than the other American mothers: "Now I am really fine, I surprise people that I'm doing so well-like I'm not grieving enough," but she later acknowledged feeling "ripped off, robbed. . . . Sometimes I think that there is something wrong with me." Another example of the greater difficulty encountered by U.S. parents in dealing with their grief is their relative inability to talk about their experience, as suggested by Ellen's words: "All I can tell you is that it is really too much to bear. . . . I don't think I have even begun to deal with it. I can't yet. I've just sort of put it out of my mind."

Some parents, primarily American ones, expressed anger, 
a key feature in the bereavement literature as reported by Pinch $(2002,291)$, whose interviewees "stopped talking at times, unable to speak and others cried and . . . sometimes parents raised their voices and almost shouted into the telephone." While some parents directed their anger at the doctors and the medical staff, others directed it toward the interviewer. This is evident in the case of Andrea (United States), who, after being fully informed about the purpose of the study and the topic of the conversation, set up an appointment for a phone interview on the next day but reacted very negatively when she was contacted: "I was doing just fine until you called. My baby died-but I was doing OK. Until now. Why are you making me do this? Why do you want me to go back to that place and time and think about all that happened? That's foul." When the interviewer offered to interrupt the interview, however, Andrea started crying but declined to do so. The interviewer apologized for having upset her and offered to hang up. Andrea did not hang up and repeated her angry words: "It's not like I'll ever forget-my baby is dead-but I was doing OK until now." The interviewer offered to meet in person ("Would it help to get together so you could let out more of your feelings about how this phone call has upset you?"), and the conversation continued for a while with many pauses and silences showing how difficult it was for Andrea to talk about her experience. She kept repeating that she had not forgotten her baby's death even if not questioned about this issue, until she finally hung up. Andrea had obviously not reached closure with her experience. In general, parents' inability to acknowledge their hostility, confusion, and anger delayed the ultimate resolution of grief.

Guilt and Self-Blame. Guilt and self-blame, both of which derive from the perception of a personal causal link to a negative decision consequence (Simos 1979; Spranca, Minsk, and Baron 1991), were commonly mentioned by the American parents who made the decision to withdraw their infants' life support. Although a sense of well-being is often emphasized regarding active participation in medical decision making, the American parents in this study did not react well to deciding the fate of their children. Bridget blamed herself: "I walk around thinking 'what if, what if?' If the vent was not removed, he would still be alive. I have been questioning myself ever since Eliot died. . . . They should have given me enough time to overcome my fears." Sharon described her ordeal with terrible words: "I felt I played a part in an execution. I should not have done it." Debra tried to overcome her guilt by adhering to fatalism and telling herself that the outcome was meant to be, that "this was in God's plans" (Fischer, Otnes, and Tuncay 2007). In contrast, the experience of guilt was never mentioned or even indirectly expressed in the French parents' narratives. Despite enduring the same loss as the Americans, the French parents seemed to have benefited from not being directly involved in the decision, as in the case of Nora: "No one could do anything. I never blamed myself. I don't want to hold a grudge against anyone."
Ambivalence about Autonomy. The American parents did not seem to have come to terms with either their children's deaths or the terrifying recognition that they consented to withdraw the life-sustaining therapy. Contrary to the assumption of the autonomous model that patients (or their surrogates) want and should make medical decisions, American parents showed an ambivalent attitude toward decision autonomy. Most of the American parents seemed satisfied to have participated in treatment decisions, but at the same time they also wished they did not have to experience the burden of choosing to withdraw life-sustaining therapy. For example, Bridget demonstrated her anger with the following words: "Stop cutting on my baby. They should have asked me first. . . . They never ask the mother"; but she also asked herself, "How did they get me to do that? . . . Now I live with having made the decision." Melissa commented, "It was the hardest decision and I needed help. It was like signing her life away."

French parents seemed similarly ambivalent about having the physicians make the treatment choice. Several of them welcomed the idea of not deciding, as represented by Sabine's comment: "I wanted to participate in the decision knowing that in any case, it is the physician who had the predominant power. Even if they'd asked us our opinion directly, we'd made the decision the way that they were telling us to." Others, however, voiced their disappointment at not having been asked to decide, as in the contradictory statements of Denise, who claimed, "I prefer that [the doctors] make the decision" but also remarked, "The physicians shouldn't be the only persons to say to stop," and Corinne, who was upset that she was not involved in the decision to limit the life-sustaining treatment but also said that if the doctors had proposed withdrawing treatment she "might have accepted it, yes. . . . It's true that the mother is not asked to choose because the doctors don't want to upset her, I'm for that."

The lack of an active choice for the French parents appeared to lessen the psychological distress associated with the death of their babies. As Nora stated, "I don't regret 'having decided' because I didn't decide, as a mother, to stop my son's life. . . . If he [the physician], as a specialist, with his experience and competence, thinks that there is a problem like that, it isn't me as the mother, who knows nothing about neonatology, to say 'yes, but' . . . I didn't want to take the risk." Pierre expressed similar feelings by saying, "They [the doctors] make the decision and then they discuss it with the parents. Since we are parents, if we had to help with a decision like that, I think it'd be impossible. It is already difficult as it is, without adding extra stress."

These results are consistent with the different discourses of self-management and restitution, scientific rationalism, and fatalism that individuals can use when undergoing important medical decisions (Fischer et al. 2007; Wong and King 2008). Given that recognizing the self as cause of a negative outcome determines major emotional distress (Weiner 1986), parents spoke directly of the psychological burden that resulted from being involved in the decision leading 
to their children's death. Parents appeared to resent situations that would coerce them into the self-attribution of a choice they could not handle. This preference for eschewing choice, however, conflicts with norms that, in most Western cultures, consider self-management and personal responsibility appropriate and almost necessary to be suitable individuals and parents (Wong and King 2008). Sharon (United States) expressed this ambivalence with the following words: "What we had to do was right for Charlie but I felt against it. . . . I have mixed feelings about it." Resorting either to scientific rationalism or to fatalism to explain a tragic outcome would help parents externalize the attribution of responsibility without breaking cultural norms, as in the words of Bridget (United States): "I can't say that God had taken him; that would have been easier. . . . I feel a strong sense that I let [my child] down." These alternatives are precluded in the world of autonomy; however, in a paternalistic world parents can try to escape self-attribution, and alleviate their pain, by relying on their faith in science and doctors.

Preference for Information. Parents' ambivalence about autonomy in decision making did not correspond to an ambivalent attitude toward being informed about either the medical conditions of their children or the available treatment alternatives. Both American and French parents showed a desire to receive an adequate level of information, as in the words of Annie (France): "The worst is not to know . . . because either you have illusions and then disappointment is all the stronger, or, on the contrary, you see things in a very negative way, you imagine thousand and thousand possibilities." American parents desired to be prepared when making the treatment limitation decision, as remarked by Melissa: "I made sure I knew everything. . . . They [the doctors] said I was a good parent because I knew the consequences"; and Debra: "They couldn't give me any percentages. If they had said 'I give you $40 \%$ that she'll survive' I would've gone for the surgery." On the other hand, French parents' eagerness to be informed, despite their passive role in the decision-making process, reflected their desire to ensure the correctness and transparency of the doctors' decision making, as voiced by Nora: "Things happened and they always informed me. So for me the truth that I had was good enough. . . . There wasn't any ambiguity, there wasn't anything left unsaid."

Doctors' willingness to share information had a positive effect on French parents by decreasing the level of uncertainty of the decision. This is evident in the words of Annie: "I don't have all the pieces of information, the ultrasounds and so on. I have no expertise whatsoever to evaluate the real condition of my baby. . . . The physicians are the ones who can evaluate the damages, who know what to do and to ask a parent to withdraw or not, that is too hard."

In contrast, the information given by the doctors did not seem to assuage the grief of American parents, who overall appeared less confident in the doctors' ability to identify the best possible course of action, as mentioned by Sharon: "I trusted the doctors and they knew he was going to get worse even though I knew in my heart that they didn't know." The French parents tried to find a deeper positive meaning in the withdrawal decision, while the American parents seemed to find no solace or meaning in it. For example, American parents rarely justified their choice by mentioning the futility of continued care, whereas French parents often validated the doctors' choice to withdraw care by considering it a way to end their infants' suffering, as in the words of Annie: "Today, taking into account what occurred, it was better. . . What relieves me is to know that they [the doctors] didn't continue with futile interventions, that at least they had really done everything they could." Consistent with scientific rationalism (Fischer et al. 2007), French parents seemed indeed to rely more on the authority of medical expertise than American parents. This might have reduced any parental doubts regarding the appropriate course of action taken by the physicians, thereby alleviating their emotional pain.

\section{Discussion}

The results of the qualitative analysis of the in-depth interviews are consistent with the conclusions reached by Orfali and colleagues in relation to a broader set of medical decisions and outcomes (Orfali 2004; Orfali and Gordon 2004). As hypothesized, American parents who made the tragic choice of withdrawing life support, thereby causing the death of their children, expressed highly negative emotions, whereas French parents, who experienced the same decision and the same outcome but did not personally make the choice, reported a lower level of grief. Also as hypothesized, both American and French parents were somewhat averse to being decision makers, questioning their preference for making a personal choice relative to having that choice externally made. This aversion for decision making, however, did not correspond to a preference for not being involved in the decision altogether, as illustrated by parents' desire to be informed by the doctors. Importantly, American parents' tendency to express more guilt and self-blame for the decision outcome suggested that greater perceived causality may have a role in explaining these results.

Interestingly, these results contrast the predictions of cognitive dissonance theory, suggesting that, following an undesirable decision outcome, choosers would find ways to convince themselves of the superiority of that outcome and subjectively bolster its value (Festinger 1957). The need to reduce cognitive dissonance explains classic findings showing that the provision and exercise of choice increase positive affect, whereas choice restrictions increase negative affect (Brehm 1966; Seligman 1975; Taylor and Brown 1988). Cognitive dissonance reduction is facilitated, however, by choosers' belief that they had freely opted to make the choice leading to the undesirable outcome. On the contrary, our results about parents' ambivalence toward autonomy indicate that choosers might have been reluctant to make that choice, which could have mitigated cognitive dissonance.

To measure the effects of choice on emotions and desire 
for autonomy and isolate the perceived causality explanation proposed in this article from alternative accounts, we expanded upon the findings from the qualitative analysis by conducting three laboratory experiments. Study participants were asked to imagine being the parents of a severely ill baby in a NICU and either choosing themselves or witnessing the doctors choose whether or not to withdraw lifesustaining therapy. Convergent results from different samples and methodologies would increase the theoretical and practical relevance of our investigation (Fine and Elsbach 2000).

Study 1 specifically explored the finding that French parents, despite their lack of direct involvement in the decisionmaking process, were as eager as American parents to be informed about medical treatments. In line with prior research showing that patients who relinquish decision making to physicians expect them to use normative, compensatory decision-making strategies in which all the alternatives are considered (Kahn and Baron 1995), this observation suggested that nonchoosers were willing to carefully check the process adopted by those choosing on their behalf. Physicians' tendency to conceal information about alternative choice options in order to protect parents' well-being (Orfali 2004) could therefore backfire if parents felt misinformed, aggravating the psychological pressure that characterizes tragic choices. On the other hand, this tendency could benefit parents as prior research has shown that an option is likely to be judged more positively when seen in isolation than when compared to other choice-set options because loss aversion emphasizes its relative disadvantages (Brenner, Rottenstreich, and Sood 1999).

To test the effect of information availability, in study 1 we manipulated the amount of information about treatments available to nonchoosers. The loss-aversion explanation would predict that nonchoosers would be better off than choosers only when they were not informed about the existence of treatments other than the one chosen by the doctor. In contrast, the perceived-causality explanation proposed in this article does not depend on information content, so that, with the same amount of information, differences in emotional responses would be determined solely by differences in the perceived causality of choosers and nonchoosers.

Study 1 also accounted for the possibility that the physicians' decision to conceal information about alternative treatments would reduce the level of uncertainty of the prognosis. To do so, we measured participants' decision confidence. If the interviewed parents were responding to different levels of uncertainty suggested by the physicians' decision framing, then study participants should report a greater level of confidence when the decision was made for them by the doctors than when it was personally made.

\section{LABORATORY STUDY 1}

\section{Method}

In study 1 we created vignettes describing decision-making contexts similar to the real-life situations from the qual- itative study and used a questionnaire to measure participants' responses to these hypothetical scenarios. We controlled for the possibility that different cultural and personal backgrounds could influence individuals' reactions to decisionmaking autonomy by randomly assigning participants to the experimental conditions. Additionally, we controlled for the loss-aversion explanation by comparing two no-choice conditions in which a doctor makes the same decision either with or without considering all the treatment alternatives.

One hundred seventy-seven undergraduate students from Cornell University were offered extra class credit to participate in a 15-minute, between-subjects study. Participants were randomly assigned to one of three conditions: choice, informed no-choice, or uninformed no-choice (see the appendix). The opening of the scenarios, which did not vary across the choice conditions, described Julie, a premature baby admitted to the NICU of a renowned hospital due to a brain hemorrhage. Her life is sustained by a ventilator, but after 3 weeks of treatment her health has not improved. The doctors summon Julie's parents to explain the situation. In the choice condition, the vignette continued with the doctors giving Julie's parents a choice between continuing the treatment (resulting in a $40 \%$ chance of death or crippling neurological impairment if Julie survives) or withdrawing the treatment (resulting in Julie's death with certainty). Participants in the choice condition were asked to play the role of Julie's parent and choose which course of action to pursue. In the informed no-choice condition, the doctors describe to the parents both courses of action and their consequences but explain that they have decided in Julie's best interest to withdraw the treatment. In the uninformed nochoice condition, the doctors make the decision to withdraw treatment but without explicitly mentioning the option to continue the treatment and its associated outcome probabilities.

Participants then completed a questionnaire. Their overall emotional response was measured by providing a list of emotional states and asking them to rate "How well each of these emotional states describes your mood as a consequence of the treatment decision." To ensure consistency with the field study, the list included six negative emotion items (nervous, upset, unhappy, distressed, concerned, guilty), based on the emotions most often mentioned by the bereaved interviewed parents. To check our assumption that making tragic choices, unlike other emotionally difficult choices, generates negative affect even when an optimal alternative is selected-in this case the treatment withdrawal alternative (Orfali 2004)—we measured participants' decision confidence by asking: "How confident are you that the best decision was made?" Preference for decision autonomy was assessed by ratings of one's own condition: "How much did you like having (not having) to make this decision?" and opposite condition: "How much would you rather have had the doctors making this decision (have made this decision yourself)?" Responses were given on a 1 (not at all) to 9 (extremely) scale. 


\section{Results}

Treatment Preferences. Seventy-one percent of choosers $\left(\chi^{2}(1)=11.88, p<.001\right)$ decided to interrupt the lifesupport treatment. As in the case of the qualitative study, the following analyses compared choosers who decided to withdraw the treatment to nonchoosers for whom the treatment withdrawal was decided by the physicians; choosers who decided to continue the treatment were dropped from the analyses. All the 158 remaining participants were confronted with the baby's death caused by the withdrawal decision. Forty-seven of these participants were in the choice condition, 54 in the informed no-choice condition, and 57 in the uninformed no-choice condition. To ensure that the study's results were not biased by participants' self-selection, all the analyses conducted on the partial data set and reported below were repeated considering the full data set, yielding substantially identical results.

Emotional Response. How intense were participants' emotions across choice conditions? We collapsed the emotional items (nervous, upset, unhappy, distressed, concerned, guilty, $\alpha=.76$ ) into a negative affect score and conducted a one-way ANOVA with choice (choice, informed nochoice, uninformed no-choice) as the independent variable. This analysis revealed a main effect for choice $(F(2,155)$ $=5.83, p<.005)$, such that informed nonchoosers experienced less negative affect $(M=6.61, \mathrm{SD}=1.80)$ than choosers $(M=7.35, \mathrm{SD}=1.35 ; F(2,155)=6.25, p<$ $.05)$ and uninformed nonchoosers $(M=7.53, \mathrm{SD}=1.28$; $F(2,155)=10.56, p<.005)$, whereas choosers and uninformed nonchoosers did not differ in negative affect $(F(2$, $155)<1$, NS).

Decision Confidence. To test the assumption that the negative affect caused by making a tragic choice does not depend on participants' confidence that the optimal choice was selected, we submitted the responses to the question about decision confidence to a one-way ANOVA with choice as the independent variable. This analysis yielded a main effect for choice $(F(2,155)=4.90, p<.01)$. Choosers $(M=6.77, \mathrm{SD}=2.25)$ reported greater confidence than either informed $(M=5.59, \mathrm{SD}=2.54 ; F(2,155)=6.14$, $p<.05)$ or uninformed $(M=5.39, \mathrm{SD}=2.31 ; F(2,155)$ $=8.71, p<.005)$ nonchoosers, whereas the two groups of nonchoosers felt the same level of decision confidence $(F(2$, $155)<1$, NS).

Preference for Autonomy. Do tragic choices reduce individuals' desire for decision-making autonomy? Two one-way ANOVAs with choice as the independent variable were conducted on the two measures of participants' preference for choosing. The ANOVA on participants' preference for being in their assigned choice condition yielded a significant main effect for choice $(F(2,155)=57.00, p<$ $.0001)$. Subsequent contrast analyses revealed that choosers $(M=1.60, \mathrm{SD}=1.56)$ liked their condition less than either informed $(M=6.54, \mathrm{SD}=2.52 ; F(2,155)=100.2, p<$ $.0001)$ or uninformed nonchoosers $(M=5.77, \mathrm{SD}=2.99$;
$F(2,155)=73.24, p<.0001)$, while the difference between the two no-choice conditions was not significant $(F(2,155)$ $=2.65, \mathrm{NS})$. The ANOVA on participants' preference for switching to the other choice condition also showed a main effect for choice $(F(2,155)=8.46, p<.001)$. Choosers $(M=2.74, \mathrm{SD}=2.36)$ were less willing to switch to the other choice condition than both informed $(M=4.76, \mathrm{SD}$ $=2.68 ; F(2,155)=14.67, p<.001)$ and uninformed nonchoosers $(M=4.48, \mathrm{SD}=2.80 ; F(2,155)=11.09$, $p<.001)$, who were equally willing to switch $(F(2,155)<$ $1, \mathrm{NS})$.

\section{Discussion}

The findings from study 1 were in keeping with the observations from the analysis of the in-depth interviews. Controlling for the type of decision (withdrawing the treatment) and the decision outcome (death of the baby) as well as for population differences across participants and the information received, the results of this vignette study showed that nonchoosers, who did not face the emotional burden of making a tragic choice, experienced a less negative affective response than choosers. Consistent with the field study's finding that parents benefited from being informed, nonchoosers' emotional advantage disappeared when the selected treatment was not compared to its alternatives. This result supports our perceived causality explanation against the alternative loss-aversion explanation, which would predict different levels of information about the choice-set options to drive variations in emotional responses.

Results of study 1 do not support the possibility that the lower uncertainty of the prognosis, rather than the psychological correlates of choosing, can explain nonchoosers' less negative response to tragic choices. If this were the case, we would expect nonchoosers in study 1 to be more confident in the decision than choosers, whereas our findings showed the opposite: choosers expressed more decision confidence than both informed and noninformed nonchoosers. This result further indicates that, in agreement with our definition of tragic choices, choosers' emotional responses were determined less by considerations about which option is best than by the level of psychological pain experienced during the decision process: the majority of choosers made the "right" decision by selecting the medically dominant alternative of withdrawing life support, reported greater confidence than nonchoosers that the best decision was made, and yet felt worse for having made it.

Also consistent with the qualitative study results, participants were ambivalent toward making the painful choice, revealing a weak preference for decision autonomy. Choosers liked their choice condition less than nonchoosers but also liked the idea of switching to the opposite condition less than nonchoosers. This result diverges from Kahn and Baron's research (1995), which found participants to be willing to relinquish hypothetical treatment choices to physicians in a nonexperimental setting. This difference could be due to the fact that relinquishing one's choice to a physician is itself a decision, while defaulting to a physician-imposed 
choice provides no decision-making power. Moreover, as suggested by the analysis of the parents' narratives in the qualitative study, making a life-or-death choice for a baby is so consequential that participants might have struggled between the moral imperative to take on the decision-making burden and the desire to avoid the pain associated with it (Schneider 1998).

The decision to withdraw treatment is medically dominant for the types of situations examined in this article (Orfali 2004). It is therefore not surprising that treatment withdrawal was preferred by parents and doctors in the qualitative study, as it was by choosers in study 1 . What about the nonchoosers whose preferences did not coincide with the doctors' decision? This question has important public policy implications in addition to being of theoretical interest. Study 2 therefore examined the extent to which our findings were dependent on the chosen course of action. As choosers' and nonchoosers' affective responses in study 1 did not appear to depend on the quality ("right or wrong") of the choice, but rather on its tragic nature, we expected that differences in affect would persist regardless of individual preferences for the option that was chosen or imposed. To test this prediction, in study 2 we measured nonchoosers' preferences and examined emotions and desire for autonomy among choosers and nonchoosers confronted by the less-preferred option of continuing the treatment. We predict that even though nonchoosers have a less-preferred option imposed, it will still be the choosers who experience greater pain.

\section{LABORATORY STUDY 2}

\section{Method}

One hundred and forty-six students, mostly undergraduates, from Cornell University participated in this 15-minute study in exchange for extra class credit. Study 2's procedures were identical to those of study 1 , except that in the nochoice condition the physicians selected the less-preferred treatment option (treatment continuation) instead of the more-preferred one (treatment withdrawal). Nonchoosers' individual treatment preferences were assessed at the end of the questionnaire by asking them to indicate which of the two treatments they would have chosen. We used this information to create a preference factor with two levels: (1) preference for treatment withdrawal, where choosers opted for withdrawing the treatment and nonchoosers indicated that, in contrast with the doctor's decision, they would have selected the withdrawal alternative; (2) preference for treatment continuation, where both choosers and nonchoosers indicated treatment continuation as their preferred alternative.

The study is therefore a 2 (choice: choice vs. no choice) $\times 2$ (preference: withdraw vs. continue) between-subjects factorial design. The choice factor was manipulated using the same choice and informed no-choice vignettes as study 1; the dependent variables were measured by using the same questionnaire except for the addition of the word "sad" to the list of emotions.

\section{Results}

Treatment Preferences. Participants in the choice condition preferred the withdraw option as in study $1,69.37 \%$ $\left(\chi^{2}(1)=16.66, p<.0001\right)$, while participants in the nochoice condition did not, $57.14 \%\left(\chi^{2}(1)<1\right.$, NS $)$. Because continuing treatment was the less-preferred course of action in the choice condition, the process of obtaining sufficient cell sizes for this analysis resulted in 77 participants in the choice withdraw condition, 20 in the no-choice withdraw condition, 34 in the choice continue condition, and 15 in the no-choice continue condition. Type III sums of squares were used to control for the unbalanced cell size, resulting in unbiased and more conservative analyses (Freund and Littell 1981; Iacobucci 1995).

Emotional Response. As in study 1, the negative emotions (nervous, upset, unhappy, distressed, concerned, guilty, sad, $\alpha=.83$ ) were combined into an overall score and submitted to a 2 (choice: choice vs. no choice) $\times 2$ (preference: withdraw vs. continue) ANOVA. As expected, this analysis yielded only a significant main effect for choice $(F(1,141)=4.34, p<.05)$ but no significant main effect for preference $(F(1,141)=1.87, \mathrm{NS})$ or choice $\times$ preference interaction $(F(1,141)<1$, NS). These results replicated study 1 and showed that treatment preferences did not influence affective reactions to tragic choices: regardless of the selected option, choosers felt worse than nonchoosers $\left(M_{\text {choice }}=6.97, \mathrm{SD}=1.40, M_{\text {no choice }}=6.25, \mathrm{SD}=1.78\right)$.

Decision Confidence. To check participants' confidence that the best decision was made, in spite of whether or not this decision was the optimal one, we conducted the two-way ANOVA for choice, preference, and their interaction on decision confidence as we did in study 1 . This analysis yielded a main effect for choice $(F(1,141)=16.18$, $p<.0001)$, a main effect for preference $(F(1,141)=6.13$, $p<.05)$, and a choice $\times$ preference interaction $(F(1,141)$ $=7.08, p<.01)$. Replicating the results of study 1 , choosers $(M=6.50, \mathrm{SD}=2.02)$ reported greater confidence than nonchoosers $(M=4.63, \mathrm{SD}=2.58)$. In addition, those who preferred the continuation of treatment $(M=6.27, \mathrm{SD}$ $=2.17$ ) were more confident that the best decision was made than those who preferred the withdrawal of treatment $(M=5.94, \mathrm{SD}=2.37)$. Thus, although choosers' confidence was greater than nonchoosers' in the preference for withdrawal condition $\left(M_{\text {choice }}=6.52, \mathrm{SD}=1.98, M_{\text {no choice }}\right.$ $=3.70, \mathrm{SD}=2.45 ; F(1,141)=28.20, p<.0001)$, in the preference for continuation condition choosers' confidence was not different from that of nonchoosers $\left(M_{\text {choice }}=6.44\right.$, $\mathrm{SD}=2.15, M_{\text {no choice }}=5.87, \mathrm{SD}=2.26 ; F(1,141)<1$, NS).

Preference for Autonomy. The two 2 (choice: choice vs. no choice) $\times 2$ (preference: withdraw vs. continue) ANOVA on participants' liking of their own condition yielded the expected main effect for choice, in which choosers liked their condition less than nonchoosers $\left(M_{\text {choice }}=\right.$ $1.74, \mathrm{SD}=1.62, M_{\text {no choice }}=4.00, \mathrm{SD}=2.44 ; F(1,141)$ 
$=44.47, p<.0001)$. Unexpectedly, the main effect for preference $(F(1,141)=4.08, p<.05)$ and the choice $\times$ preference interaction $(F(1,141)=6.22, p<.05)$ were also significant. Participants who preferred treatment continuation liked their own condition more than those who preferred withdrawal $\left(M_{\text {withdraw }}=2.10, \mathrm{SD}=1.91, M_{\text {continue }}=2.63\right.$, $\mathrm{SD}=2.36$ ). Thus, although choosers always liked their condition less than nonchoosers, the difference was greater in the continue condition $\left(M_{\text {choice }}=1.62, \mathrm{SD}=1.28, M_{\text {no choice }}\right.$ $=4.93, \mathrm{SD}=2.66 ; F(1,141)=34.79, p<.0001)$ than in the withdraw condition $\left(M_{\text {choice }}=1.79, \mathrm{SD}=1.75, M_{\text {no choice }}\right.$ $=3.30, \mathrm{SD}=2.05 ; F(1,141)=10.98, p<.005)$. The same ANOVA conducted on preference for switching to the other condition yielded only a main effect for choice. Replicating the prior study's results, choosers were less likely to switch to the other condition than nonchoosers $\left(M_{\text {choice }}=\right.$ $3.18, \mathrm{SD}=2.49, M_{\text {no choice }}=5.94, \mathrm{SD}=2.33 ; F(1,141)$ $=34.12, p<.0001)$. No other effects were significant (all Fs $(1,141)<1$, NS).

\section{Discussion}

Study 2 builds on the previous studies to show that nonchoosers' emotional advantage over choosers persisted even when the treatment selected for them by the physicians was the less-preferred option of continuation and regardless of whether this decision agreed with participants' personal preferences. As in study 1, and consistent with our definition of tragic choices as independent of the quality of the outcome, choosers' feelings were more negative than those of nonchoosers despite being more confident that the best choice was made. Participants' ambivalence toward decision autonomy found in the prior studies was substantiated in study 2: nonchoosers liked their condition assignment better than choosers but were also more willing to relinquish it. Two results were, however, not predicted in the preference for continuation condition: choosers' and nonchoosers' decision confidence was equivalent, and nonchoosers' liking for their choice condition increased. A positive surprise effect could account for these results, given the lower likelihood that an externally made choice would satisfy a lesspreferred treatment option.

Although these findings support the hypothesis that choosers' greater perceived causality intensifies negative emotions in tragic choices, this psychological mechanism has not yet been directly tested. Prior research suggested that the extent to which choosers perceive themselves as causal agents in what they will experience makes the act of choosing more or less meaningful, which in turn influences the magnitude of the consequences of choosing. For example, Botti and McGill (2006) showed that choosers' evaluation of a decision outcome is not different from that of nonchoosers when the available information is nondiagnostic of the relative quality of the choice-set options. When choosers cannot significantly distinguish among options, the act of choosing is less meaningful as it is perceived as not directly contributing to the ultimate experience with the selected outcome.
Study 3 was therefore designed with the objective of decreasing the perception of personal causality associated with choice in order to make the act of choosing less meaningful, thereby attenuating the impact of choice on choosers' emotional responses. In study 3 the treatment withdrawal option was framed by the doctors as being the only option worth pursuing from a medical perspective (Orfali 2004). By framing this option as an objective medical fact rather than a matter of personal opinion, choosers could perceive their selection less as a result of their own actions, shifting the locus of causality from the self to the physicians and resulting in lower distress and greater desire for autonomy.

\section{LABORATORY STUDY 3}

\section{Method}

One hundred and forty-five students, mostly undergraduates, from Cornell University took part in this 15-minute study in exchange for extra class credit. The study was a 2 (choice: choice vs. no choice) $\times 2$ (frame: frame vs. no frame) between-subjects design. Participants in the two choice conditions were presented with vignettes identical to those read by choosers and informed nonchoosers in study 1 , except for a concluding sentence added to manipulate the frame factor. Choosers in the no-frame (frame) condition read the doctors saying to the parents, "We know that this is a difficult decision, but these are your options and (in our opinion, there is nothing else to be done but withdrawing the treatment; however,) you have to tell us what to do," while nonchoosers in the no-frame (frame) condition read the doctors saying, "We know that this is a difficult decision, but these are the options and because of the baby's critical condition (in our opinion there is nothing else to be done but withdrawing the treatment. So,) we decided to withdraw the treatment." Participants' emotional responses and preferences for autonomy were assessed with the same questions used in study 2.

\section{Results}

Treatment Preferences. As in study 1, a chi-square analysis conducted on choosers' treatment preferences revealed that, across the two frame conditions, the majority of choosers opted for withdrawal $\left(74.42 \%, \chi^{2}(1)=20.51\right.$, $p<.0001)$. The analysis also revealed that this preference was not a function of framing (preference $\times$ frame: $\chi^{2}(1)$ $=0.77, \mathrm{NS})$. We controlled for decision type by dropping the choice participants who opted for treatment continuation. Therefore, the following analyses refer to the answers of 123 study participants, 28 in the choice no-frame condition, 36 in the choice frame, 28 in the no-choice no-frame condition, and 31 in the no-choice frame condition. As with study 1 , however, the analyses conducted on the whole data set yielded substantially equivalent results.

Emotional Response. The seven negative emotional items used in study 2 to assess affective response were com- 
bined into a negative affect score $(\alpha=.81)$. The 2 (choice, no choice) $\times 2$ (frame, no frame) ANOVA conducted on this score yielded the expected choice $\times$ frame interaction $(F(1,118)=4.63, p<.05)$ but no significant effects for choice $(F(1,118)=3.31, \mathrm{NS})$ or frame $(F(1,118)<1$, NS). Contrast analyses revealed the anticipated pattern (see fig. 1). Replicating prior studies, choosers in the no-frame condition $(M=7.42, \mathrm{SD}=1.39)$ felt more negatively than nonchoosers $(M=6.40, \mathrm{SD}=1.26 ; F(1,118)=7.30, p$ $<.01$ ); however, in the frame condition the difference between choosers and nonchoosers' negative affect was not significant $\left(M_{\text {choice }}=6.81, \mathrm{SD}=1.65, M_{\text {no choice }}=6.89\right.$, $\mathrm{SD}=1.26 ; F(1,118)<1, \mathrm{NS})$.

Preference for Autonomy. The same two-way ANOVA conducted on participants' liking for their choice condition yielded a main effect for choice $(F(1,119)=29.50, p<$ $.0001)$ and a choice $\times$ frame interaction $(F(1,119)=5.94$, $p<.05)$ but no frame effect $(F(1,119)=2.29$, NS $)$. As in study 1 , choosers $(M=1.48, \mathrm{SD}=1.14)$ preferred their choice condition less than nonchoosers $(M=3.14, \mathrm{SD}=$ 2.26). This difference was, however, greater in the no-frame condition $\left(M_{\text {choice }}=1.32, \mathrm{SD}=0.98, M_{\text {no choice }}=3.79\right.$, $\mathrm{SD}=2.42 ; F(1,119)=28.49, p<.0001)$ than in the frame condition $\left(M_{\text {choice }}=1.61, \mathrm{SD}=1.24, M_{\text {no choice }}=\right.$ $2.55, \mathrm{SD}=1.96 ; F(1,119)=4.90, p<.05)$. The ANOVA conducted on participants' preference for switching to the other choice condition revealed a main effect for choice $(F(1,119)=46.32, p<.0001)$, whereby choosers $(M=$ 3.75 , SD $=2.78$ ) were less willing to switch than nonchoosers $(M=6.78, \mathrm{SD}=2.05)$. No other effects were significant (all $F_{\mathrm{S}}(1,119)<1$, NS).

\section{Discussion}

Results of study 3 replicated prior findings by showing that, when the decision was not framed as medically superior, participants who personally made a tragic choice were emotionally worse off than those who experienced the same decision (treatment withdrawal) and outcome (the baby's death) but did not make the choice themselves. However, when the physician-selected decision was framed as medically superior, choosers' and nonchoosers' emotional responses were the same. These results support our explanation that choosers' affect would be mitigated by the decrease in perceived causality created by the framing.

Also consistent with prior results, study 3 revealed that choosers did not enjoy making the treatment choice but at the same time were unwilling to have the physicians choose for them; similarly, nonchoosers liked having the physicians choose on their behalf but were also willing to make this choice on their own. Participants' dislike for making tragic

FIGURE 1

STUDY 3: INTERACTION BETWEEN CHOICE AND FRAMING ON NEGATIVE EMOTIONAL RESPONSE

Negative emotions

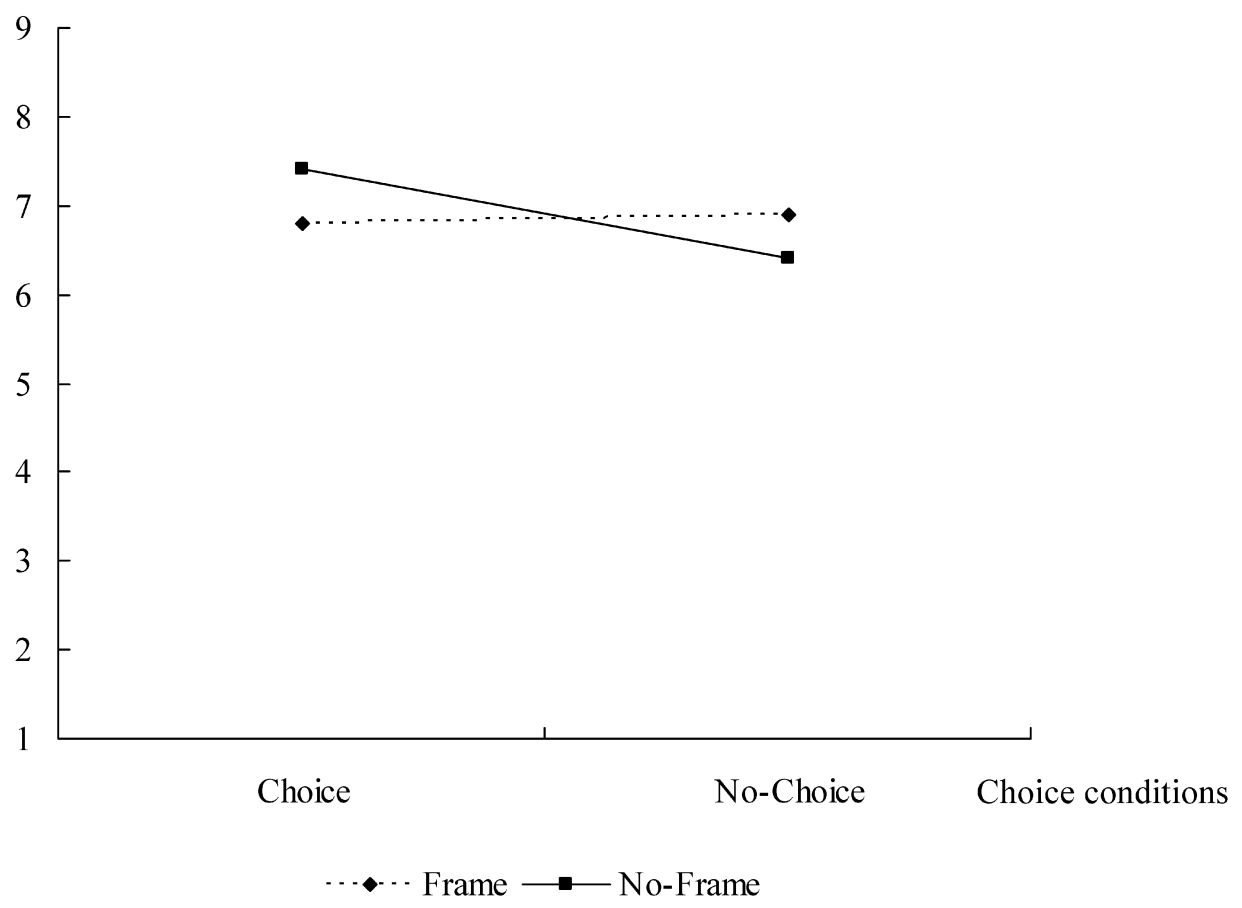


decisions was attenuated only in the framing context, supporting the idea put forward in prior research that factors influencing reactions to personally made and externally dictated choices do not necessarily have an impact on preference for decision autonomy (Botti and McGill 2006).

\section{GENERAL DISCUSSION}

The outcry recently provoked in the United States by the case of Terri Schiavo, a woman in a permanent vegetative state whose life-sustaining treatment was withdrawn after 7 years of legal battle between her husband and parents, testifies to the general public's sensibility toward tragic choices (Goodnough 2005). The Schiavo incident divided the nation as U.S. government institutions, media, and public opinion debated about who should decide in cases of life-and-death choices, demonstrating the psychological impact of tragic choices not only on the parties involved in the decision but on every single citizen. The findings from our investigation suggest that tragic choices emotionally condemn choosers in spite of their confidence that the optimal solution was selected. This psychological turmoil manifests itself in ambivalence toward decision autonomy: decision makers want the choice yet simultaneously wish to relinquish it. Thus, when confronted by tragic choices, individuals are likely to be better off if those choices are either physically or psychologically removed from them.

Although the current research limited its focus to lifeand-death decisions, results can be generalized to other types of momentous and emotionally daunting choices. The mandates of current health care systems and the progress in medical technology have increased the likelihood of a person's being confronted by tragic choices for oneself and on behalf of family members, for example, whether to terminate a pregnancy based on the results of prenatal screenings for genetic disorders or whether to use therapies and drugs that trade off odds of survival and quality of life (Anand 2005; Dockser Marcus 2005; Wong and King 2008).

Our investigation of tragic choices was informed by prior research that has analyzed consumer behavior in highly consequential domains, including the coping, identity-restoration mechanisms, and risk-understanding processes of cancer patients (Pavia and Mason 2004; Wong and King 2008), bereaved families grieving for the loss of a loved one (Bonsu and Belk 2003; Gentry et al. 1995), parents pursuing parenthood using assisted reproductive technologies (Fischer et al. 2007), and elders recognizing their impending mortality (Price, Arnould, and Curasi 2000). The current article expands on these prior studies by examining the psychological consequences of personally making tragic choices versus having others making the same choices on one's behalf.

Given the magnitude of the research question, we decided to study tragic choices by adopting an unconventional multimethod approach that blended qualitative and quantitative data (Fine and Elsbach 2000). One might argue that this approach is limited by the adoption of samples that were very different from each other (i.e., bereaved parents and undergraduate students). But the agreement in the responses across these two different populations suggests that individuals who are not directly involved in tragic choices have similar experiences to those who are. This is an important finding because it shows not only that the detriments of making tragic choices are more stable and universal than assumed in the literature, but also that public policy makers and physicians who are not personally involved in these choices can and should take into account the psychological distress of citizens and patients who are called to make them.

While conducting the laboratory studies we deliberately ignored cultural differences among participants to isolate the role of perceived causality in the act of choosing. Although cultural differences are important in explaining how consumers react to self- versus other-made choices, prior research shows that Americans may be more, rather than less, predisposed to appreciate the benefits of choosing (Iyengar and Lepper 1999). Thus, our results from the laboratory studies conducted in the United States indicating a reduced preference for making tragic choices and more negative consequences on choosers' subjective well-being are even more surprising.

These results pose a dilemma in the United States, where decision autonomy is considered to be beneficial to patients: is it more socially desirable to prevent patients' self-determination but protect their emotional welfare or to have autonomous but unhappy patients? Study 3 suggests a possible solution to this dilemma by demonstrating that decision framing may reduce the emotional disadvantages of decision autonomy while still preserving patients' rights to choose. Entitling doctors to decision framing, however, raises other important ethical issues. Prior research shows that choosers faced with the life-altering decision of interrupting care are particularly susceptible to physicians' influence (Hoff 2001; Orfali 2004). The extent of physicians' persuasive power is evident from study 2 , where nonchoosers not only favored the usually more-preferred withdrawal treatment just as much as the less-preferred continuation treatment when this option was selected by the doctors but also maintained more positive affect even when a nonpreferred treatment was imposed on them.

Overall, we believe that our findings suggest a more nuanced course of action than just returning to the paternalistic model. From the perspective of the patients or proxies, making tragic choices may deprive individuals of emotional resources. People should therefore evaluate the pros and cons of relinquishing decisions that may be detrimental to their well-being. From the physicians' perspective, understanding the patients' or parents' readiness to engage in decision making is probably more effective than imposing a specific decision model on all patients. The physicians' tasks, and their training, should include appreciating the differential demand for participation in medical decisions. Finally, from the policy makers' perspective, the recent focus on providing choices to patients may overshadow a more important issue: the quality of the patient-physician relationship (Hoff 2001; Orfali 2004; Orfali and Gordon 2004). Public confidence in the leaders of U.S. health care institutions has fallen since 
1966 more than it has for other major institutions (Delude 2004). At a time when patients are overwhelmed by the intensity of the choices confronting them, a supportive relationship with physicians would help their coping processes. On the contrary, research indicates that in the United States the autonomous model is often seen as a way to protect the doctors by shifting decision-making responsibility to patients and families, to the point that individuals believe that the doctors operate in their own best interest rather than in the interest of the patients (Mechanic and Schlesinger 1996).

Our modern health care system assumes the superiority of the choice paradigm with little regard for the messy realities of tragic choices. This idealized version of autonomy is one of "informed free choice" (Kukla 2007), but for better or for worse, "sick persons require the help of others to make autonomous decisions" (Cassell 2007, 23). This is equally true, if not more so, of the vulnerable lay people who will have to live with the emotional burden of having made these tragic choices.

\section{APPENDIX STUDY 1 SCENARIOS}

\section{INTRODUCTION (COMMON TO ALL CONDITIONS)}

Julie is a premature baby who was born after only 27 weeks of gestation weighing less than 2 pounds. Julie is critically ill because she has suffered a brain hemorrhage. For this reason, she has been treated in the Neonatal Intensive Care Unit of a renowned academic hospital where her life is sustained by a machine that helps her breathing. After three weeks under this life-sustaining treatment, Julie's overall health condition has not improved.

\section{CHOICE CONDITION}

The doctors summon Julie's parents . . . and offer them the choice to continue the treatment or withdraw the treatment by turning off the ventilation machine. The doctors explain to Julie's parents the consequences of this decision. If the treatment is withdrawn, Julie will die. If the treatment is continued, there is about $40 \%$ probability that Julie will die and about $60 \%$ probability that she will survive with severe neurological impairments that would confine her in bed unable to speak, walk, and interact with others.

If you were in the shoes of Julie's parents, what would you decide?

\section{INFORMED NO-CHOICE CONDITION}

The doctors summon Julie's parents . . . and inform them that there are two possible courses of action: continuing the treatment or withdrawing the treatment by turning off the ventilation machine. The doctors explain to Julie's parents the consequences of each action. If the treatment is with- drawn, Julie will die. If the treatment is continued, there is about $40 \%$ probability that Julie will die and about $60 \%$ probability that she will survive with severe neurological impairments that would confine her in bed unable to speak, walk, and interact with others. Because of Julie's critical clinical condition, the doctors decide in her best interest to withdraw the treatment.

\section{UNINFORMED NO-CHOICE CONDITION}

The doctors summon Julie's parents . . . and explain to them their decision. Because Julie's critical clinical condition implies severe neurological impairments that would confine her in bed unable to speak, walk, or interact with others, they decided in her best interest to withdraw the treatment by turning off the ventilation machine and let her die.

\section{REFERENCES}

Anand, Geeta (2005), "A Biotech Drug Extends a Life, but at What Price?” Wall Street Journal, November 16, A1.

Birch, Maxine and Tina Miller (2000), "Inviting Intimacy: The Interview as Therapeutic Opportunity," International Journal of Social Research Methodology, 3 (3), 189-202.

Bonsu, Samuel K. and Russell W. Belk (2003), "Do Not Go Cheaply into That Good Night: Death-Ritual Consumption in Asante, Ghana," Journal of Consumer Research, 30 (June), 41-55.

Botti, Simona and Sheena S. Iyengar (2004), "The Psychological Pleasure and Pain of Choosing: When People Prefer Choosing at the Cost of Subsequent Outcome Satisfaction," Journal of Personality and Social Psychology, 87 (3), 312-26.

Botti, Simona and Ann L. McGill (2006), "When Choosing Is Not Deciding: The Effect of Perceived Responsibility on Satisfaction," Journal of Consumer Research, 33 (September), 211-19.

Brehm, Jack W. (1966), A Theory of Psychological Reactance, New York: Academic Press.

Brenner, Lyle, Yuval Rottenstreich, and Sanjay Sood (1999), "Comparison, Grouping, and Preference," Psychological Science, 10 (3), 225-29.

Carmon, Ziv, Klaus Wertenbroch, and Marcel Zeelenberg (2003), "Option Attachment: When Deliberating Makes Choosing Feel Like Losing," Journal of Consumer Research, 30 (June), 15-29.

Cassell, Eric J. (2007), "Unanswered Questions: Bioethics and Human Relationships," Hastings Center Report, 37 (5), 20-23.

Chernev, Alexander (2003), "When More Is Less and Less Is More: The Role of Ideal Point Availability and Assortment in Consumer Choice," Journal of Consumer Research, 30 (September), 170-83.

deCharms, Richard (1968), Personal Causation, New York: Academic Press.

Deci, Edward L. and Richard M. Ryan (1985), Intrinsic Motivation and Self-Determination in Human Behavior, New York: Plenum.

Delude, Cathryn (2004), "Crisis of Confidence," http://www .hsph.harvard.edu/review/review_fall_04/rvw_trust.html. 
Dhar, Ravi (1997), "Consumer Preference for a No-Choice Option," Journal of Consumer Research, 24 (September), 215-31.

Dockser Marcus, Amy (2005), "A Brother's Survey Touches a Nerve in Abortion Fight," Wall Street Journal, October 3, A1.

Dunn, Dana S. and Timothy D. Wilson (1990), "When the Stakes Are High: A Limit to the Illusion-of-Control Effect," Social Cognition, 8 (3), 305-23.

Festinger, Leon (1957), A Theory of Cognitive Dissonance, Evanston, IL: Row, Peterson.

Fine, Gary A. and Kimberly D. Elsbach (2000), "Ethnography and Experiment in Social Psychological Theory Building: Tactics for Integrating Qualitative Field Data with Quantitative Lab Data," Journal of Experimental Social Psychology, 36 (1), 51-76.

Fischer, Eileen, Cele C. Otnes, and Linda Tuncay (2007), "Pursuing Parenthood: Integrating Cultural and Cognitive Perspectives on Persistent Goal Striving," Journal of Consumer Research, 34 (December), 425-40.

Freund, Rudolf J. and Ramon C. Littell (1981), SAS for Linear Models: A Guide to the ANOVA and GLM Procedures, Cary, NC: SAS Institute.

Garbarino, Ellen C. and Julie A. Edell (1997), "Cognitive Effort, Affect, and Choice," Journal of Consumer Research, 24 (September), 147-58.

Gawande, Atul (2002), Complications: A Surgeon's Notes on an Imperfect Science, New York: Picador.

Gentry, James W., Patricia F. Kennedy, Catherine Paul, and Ronald P. Hill (1995), "Family Transition during Grief: Discontinuities in Household Consumption Patterns," Journal of Business Research, 34 (September), 67-79.

Gilbert, Daniel T., Elizabeth C. Pinel, Timothy D. Wilson, Stephen J. Blumberg, and Thalia P. Wheatley (1998), "Immune Neglect: A Source of Durability Bias in Affective Forecasting," Journal of Personality and Social Psychology, 75 (3), 617-38.

Gilovich, Thomas, Victoria Husted Medvec, and Serena Chen (1995), "Commission, Omission, and Dissonance Reduction: Coping with Regret in the 'Monty Hall' Problem," Personality and Social Psychology Bulletin, 21 (2), 182-90.

Goodnough, Abby (2005), "Behind Life-and-Death Fight, a Rift That Began Years Ago," http://www.nytimes.com/2005/03/ 26/national/26families.html.

Guadagnoli, Edward and Patricia Ward (1998), "Patient Participation in Decision-Making," Social Science and Medicine, 47 (3), 329-39.

Hoff, Lee Ann (2001), People in Crisis: Clinical and Public Health Perspectives, San Francisco: Jossey-Bass.

Hofstede, Geert (2001), Culture's Consequences: Comparing Values, Behaviors, Institutions, and Organizations across Nations, Thousand Oaks, CA: Sage.

Hotelling, Harold (1929), "Stability in Competition," Economic Journal, 39 (153), 41-57.

Iacobucci, Dawn (1995), "The Analysis of Variance for Unbalanced Data," in Marketing Theory and Applications, Vol. 6, ed. David W. Stewart and Naufel J. Vilcassim, Chicago: American Marketing Association, 337-43.

Iyengar, Sheena S. and Mark R. Lepper (1999), "Rethinking the Value of Choice: A Cultural Perspective on Intrinsic Motivation," Journal of Personality and Social Psychology, 76 (3), 349-66.

(2000), "When Choice Is Demotivating: Can One Desire
Too Much of a Good Thing?" Journal of Personality and Social Psychology, 79 (6), 995-1006.

Kahn, Barbara E. and Jonathan Baron (1995), "An Exploratory Study of Choice Rules Favored for High-Stakes Decisions," Journal of Consumer Psychology, 4 (4), 305-28.

Kahn, Barbara E. and Mary Frances Luce (2003), "Understanding High-Stakes Consumer Decisions: Mammography Adherence Following False-Alarm Test Results," Marketing Science, 22 (3), 393-410.

Kahneman, Daniel and Jason Riis (2005), "Living, and Thinking about It: Two Perspectives on Life," in The Science of WellBeing, ed. Felicia A. Huppert, Nick Baylis, and Barry Keverne, Oxford: Oxford University Press, 285-304.

Katz, Jay (1984), The Silent World of Doctor and Patient, Baltimore: Johns Hopkins University Press.

Kukla, Rebecca (2007), "How Do Patients Know?" Hastings Center Report, 37 (5), 27-35.

Landman, Janet (1987), "Regret and Elation Following Action and Inaction: Affective Responses to Positive versus Negative Outcomes," Personality and Social Psychology Bulletin, 13 (4), 524-36.

Langer, Ellen J. (1975), “The Illusion of Control,” Journal of Personality and Social Psychology, 32 (2), 311-28.

Luce, Mary Frances (1998), "Choosing to Avoid: Coping with Negatively Emotion-Laden Consumer Decisions," Journal of Consumer Research, 24 (March), 409-33.

Luce, Mary Frances, James R. Bettman, and John W. Payne (1997), "Choice Processing in Emotionally Difficult Decisions," Journal of Experimental Psychology: Learning, Memory, and Cognition, 23 (March), 384-405.

Mayer, Stephan A. and Sharon B. Kossoff (1999), "Withdrawal of Life-Support in the Neurological Intensive Care Unit," Neurology, 52 (8), 1602-9.

McLean, Richard F., Jordan Tarshis, C. David Mazer, and J. P. Szalai (2000), "Death in Two Canadian Intensive Care Units: Institutional Difference and Changes over Time," Critical Care Medicine, 28 (1), 100-103.

Mechanic, David and Mark Schlesinger (1996), "The Impact of Managed Care on Patients' Trust in Medical Care and Their Physicians," Journal of the American Medical Association, 275 (21), 1693-97.

Oath of Hippocrates (ca. 400 BC/1910), in Harvard Classics, Vol. 38, Boston: Collier.

Orfali, Kristina (2004), "Parental Role in Medical Decision-Making: Fact or Fiction? A Comparative Study of Ethical Dilemmas in French and American Neonatal Intensive Care Units," Social Science and Medicine, 58 (10), 2009-22.

Orfali, Kristina and Elisa Gordon (2004), "Autonomy Gone Awry: A Cross-Cultural Study of Parents' Experiences in Neonatal Intensive Care Units," Theoretical Medicine and Bioethics, 25 (4), 329-65.

Pavia, Teresa M. and Marlys J. Mason (2004), "The Reflexive Relationship between Consumer Behavior and Adaptive Coping," Journal of Consumer Research, 31 (September), 441-54.

Pinch, Winifred J. Ellenchild (2002), When the Bough Breaks: Parental Perceptions of Ethical Decision-Making in NICU, Lanham, MD: University Press of America.

Price, Linda L., Eric J. Arnould, and Carolyn Folkman Curasi (2000), "Older Consumers' Disposition of Special Possessions," Journal of Consumer Research, 27 (September), 179-201.

Ritov, Ilana and Jonathan Baron (1995), “Outcome Knowledge, 
Regret, and Omission Bias," Organizational Behavior and Human Decision Processes, 64 (2), 119-27.

Schneider, Carl (1998), The Practice of Autonomy: Patients, Doctors, and Medical Decisions, Oxford: Oxford University Press.

Schwartz, Barry (2004), The Paradox of Choice: Why More Is Less, New York: Harper Collins.

Schwartz, Barry, Andrew Ward, John Monterosso, Sonja Lyubomirsky, Katherine White, and Darrin R. Lehman (2002), "Maximizing versus Satisficing: Happiness Is a Matter of Choice," Journal of Personality and Social Psychology, 83 (5), 1178-97.

Seligman, Martin E. (1975), Helplessness: On Depression, Development, and Death, San Francisco: W. H. Freeman.

Shafir, Eldar, Itamar Simonson, and Amos Tversky (1993), "Reason-Based Choice," Cognition, 49 (1-2), 11-36.

Simos, Bertha G. (1979), A Time to Grieve: Loss as a Universal
Human Experience, New York: Family Service Association of America.

Spranca, Mark, Elisa Minsk, and Jonathan Baron (1991), "Omission and Commission in Judgment and Choice," Journal of Experimental Social Psychology, 27 (1), 76-105.

Strauss, Anselm and Juliet Corbin (1990), Basics of Qualitative Research: Grounded Theory Procedures and Techniques, Newbury Park, CA: Sage.

Taylor, Shelley E. and Jonathon D. Brown (1988), "Illusion and Well-Being: A Social Psychological Perspective on Mental Health," Psychological Bulletin, 103 (2), 193-210.

Weiner, Bernard (1986), An Attributional Theory of Motivation and Emotion, New York: Springer-Verlag.

Wong, Nancy and Tracey King (2008), "The Cultural Construction of Risk Understandings through Illness Narratives," Journal of Consumer Research, 34 (February), 579-94. 